\title{
Genital chlamydial infections in patients attending a gynaecological outpatient clinic
}

\author{
J. PAAVONEN,* P. SAIKKU,† E. VESTERINEN,* B. MEYER,* \\ E. VARTIAINEN,* AND E. SAKSELA* \\ From the *I-II Departments of Obstetrics and Gynaecology, University Central Hospital, \\ Helsinki, Finland, and †Department of Virology, University of Helsinki, Helsinki, Finland
}

SUMMARY Investigation for genital chlamydial infections was carried out on 160 patients of fertile age attending a gynaecological outpatient clinic. Thirteen $(9 \%)$ of the 144 patients with valid specimens were found to be Chlamydia-positive. Seven $(54 \%)$ of them had antichlamydial antibodies by the complement-fixation test, and $11(85 \%)$ antichlamydial antibodies by a single-antigen immunofluorescence test compared with 21 (16\%) and $70(53 \%)$, respectively, of the 131 Chlamydianegative patients. Patients with overt genital chlamydial infection often complained of ocular and urethral symptoms. Usually there was clinical evidence of cervical infection as well as of inflammation on cervicovaginal smears. Colposcopical and histological examinations did not show any specific alterations.

\section{Introduction}

Chlamydia trachomatis is an obligate, intracellular parasite causing trachoma, paratrachoma, lymphogranuloma venereum, and genitourinary infections in humans (Grayston and Wang, 1975; Schachter et al., 1976). C. trachomatis is recognised as common in the genital tract of women attending clinics for venereal diseases as well as of the sexual partners of men with nongonococcal urethritis (NGU) (Richmond and Sparling, 1976; Schachter et al., 1976; Alani et al., 1977; Rees et al., 1977).

Cervicitis and pelvic inflammatory disease in women may be aetiologically related to Chlamydia (Schachter et al., 1967; Eschenbach et al., 1975; Schachter et al., 1975a; Mårdh et al., 1977; Rees et al., 1977). Because it may possibly be associated with cervical malignancy (Alexander, 1973; Schachter et al., 1975b), this agent has also attracted attention as an important infective agent. Although chlamydial infections are not yet proved causes of cervical disease (Richmond and Sparling, 1976), it has been suggested that Chlamydia may make specific morphological alterations to cervical epithelial cells (Naib, 1970; Dunlop et al., 1976). Women with genital chlamydial infection often show a serologically detectable immunological

Address for reprints: J. Paavonen, MD, I Department of Obstetrics and Gynaecology, University Central Hospital, Haartmaninkatu 2, Helsinki, Finland 00290

Received for publication 3 January 1978 response towards antigens of the organism (Richmond and Caul, 1975, 1977).

The aims of the present work were to study prospectively the incidence and nature of genital chlamydial infection in a sample population from a general gynaecological outpatient clinic and to evaluate the diagnostic value of the methods applied in the gynaecological routine.

\section{Material and methods}

PATIENTS

The sample population consisted of 160 patients of fertile age attending the gynaecological and obstetric outpatient clinics at Helsinki University Central Hospital in September and October 1976.

The patients did not have acute symptoms but were either being examined for gynaecological disease or were under observation for hormonal, fertility, or similar problems. Postmenopausal patients and those being treated with antibiotics or sulphonamides were excluded. The mean age of the patients was 29.5 years (range 17-49). Thirty-nine patients were fitted with intrauterine devices, 22 were taking oral contraceptives, and 81 used other methods or none at all, and 18 were pregnant.

CHLAMYDIAL ISOLATION AND SEROLOGY Specimens for chlamydial isolation were collected with a sterile cottonwool swab from the endocervix 
into two SP transport media (Dunlop et al., 1972). Isolation attempts were done conventionally in irradiated McCoy cells (Darougar et al., 1971). Gentamicin was used as antibiotic.

Serum antibodies were determined by complement-fixation (CF) and indirect immunofluorescence (IF) tests. CF group antigen was prepared by the acetone-ether method from $C$. trachomatis (kindly supplied by Dr C. Mordhorst, Statens Seruminstitut, Copenhagen, Denmark) and the test was done conventionally in a microsystem. For the IF test the following method modified from the original one (Dr P. Terho, Department of Virology, University of Turku) was used. The antigen slides were prepared by growing continuous untreated epithelioid dog kidney cells (kindly supplied by Dr N. Oker-Blom, Department of Virology, University of Helsinki) on slides in Petri dishes. The cells were infected with C. trachomatis serotype $\mathrm{L} 2$ to produce inclusions acting as the antigen in the test (Saikku and Paavonen, 1978).

\section{CYTOLOGICAL AND HISTOLOGICAL TECHNIQUES}

The cytological smears obtained from the posterior vaginal fornix, the ectocervix, and the endocervix were stained according to Papanicolaou's original method. Histological samples from Chlamydiapositive patients were obtained at colposcopy, fixed in formalin, and stained with van Giesonhaematoxylin or haematoxylin-eosin using routine methods.

Colposcopy was performed with a Zeiss-Oberkochen colposcope using magnification $\times 40$. Colposcopic classification of three grades was used as described in detail elsewhere (Timonen and Meyer, 1967).

VIROLOGICAL TEST AND ISOLATION OF OTHER MICRO-ORGANISMS

Herpes genitalis was diagnosed from virus isolation specimens obtained from the cervix (Leinikki and Salo, 1973), or from characteristic alterations observed at the routine examination of the cytological smears, or from both (Naib et al., 1966; Vesterinen et al., 1977).

Genital condyloma accuminatum was diagnosed both clinically and cytologically (Purola and Savia, 1977). Cultivation of Neisseria gonorrhoeae, Trichomonas vaginalis, and yeast, as well as urine analysis for bacterial infection, was made by conventional methods (Lennette et al., 1974).

\section{Results}

Thirteen $(9 \%)$ of the 144 patients with valid isolation specimens harboured Chlamydia. In 16 patients the samples were contaminated by an overgrowth of mixed microbial flora.

Chlamydial group-specific antibodies determined by the CF test at a dilution of $1: 8$ or more were detected in seven $(54 \%)$ of the 13 Chlamydiapositive patients and in $21(16 \%)$ of the 131 Chlamydia-negative patients. Chlamydia groupspecific antibodies at a level of $1: 8$ or more determined by a single-antigen IF test were detected in $11(85 \%)$ of the Chlamydia-positive patients and in $70(53 \%)$ of the Chlamydia-negative patients. IF test titres $\geq 1: 64$ occurred in eight $(62 \%)$ of Chlamydia-positive patients and in $25(19 \%)$ of Chlamydia-negative patients (Table 1). The Figure compares antibodies detected by the CF and IF tests in sera from 13 Chlamydia-positive patients. Within two months one isolation-positive patient seroconverted ( $\geq$ fourfold rise in titre) by $\mathrm{CF}$ test and four patients by IF test.

Eight $(62 \%)$ of the 13 Chlamydia-positive patients showed clinical cervicitis with or without cervical erosion (inflammation and hypertrophy of the cervix with mucopurulent discharge) compared with $43(33 \%)$ of the 131 Chlamydia-negative patients. Thus, $16 \%$ of the 51 patients with cervical infection, $9 \%$ of the 22 patients with vaginitis only (inflamed vaginal mucosa and leucorrhoea without cervical infection), and $4 \%$ of the 71 patients with no cervicovaginal abnormalities harboured Chlamydia. How-

Table 1 Chlamydial antibody titres found in CF and IF tests of sera from patients attending a gynaecological outpatient clinic

\begin{tabular}{|c|c|c|c|c|c|c|c|c|c|c|c|c|c|c|}
\hline & $\begin{array}{l}\text { No. of } \\
\text { sera }\end{array}$ & $<8$ & 8 & 16 & 32 & 64 & 128 & 256 & 512 & 1024 & $\begin{array}{l}\text { Total } \\
\geqslant 8 \\
\text { No. }\end{array}$ & $\%$ & $\begin{array}{l}\text { Total } \\
\geqslant 64 \\
\text { No. }\end{array}$ & $\%$ \\
\hline \multicolumn{15}{|c|}{ Chlamydia-positive* } \\
\hline CF & 13 & 6 & 5 & 0 & 2 & $\mathbf{0}$ & 0 & 0 & 0 & 0 & 7 & 54 & 0 & \\
\hline IF & 13 & 2 & 0 & 1 & 2 & 2 & 2 & 3 & 0 & 1 & 11 & 85 & 8 & 62 \\
\hline \multicolumn{15}{|c|}{ Chlamydia-negative } \\
\hline CF & 131 & 110 & 10 & 8 & 3 & 0 & 0 & 0 & 0 & 0 & 21 & 16 & 0 & \\
\hline IF & 131 & 61 & 23 & 10 & 12 & 11 & 9 & 5 & 0 & 0 & 70 & 53 & 25 & 19 \\
\hline
\end{tabular}

*Highest titre observed 


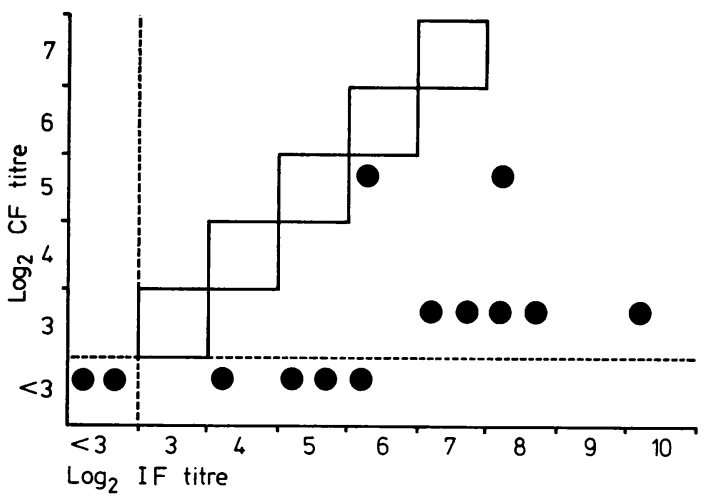

Figure Comparison of CF and IF test titres of sera from 13 Chlamydia-positive women

ever, Chlamydia-negative patients with cervicovaginal infection were significantly $(P<0.005)$ more often seropositive by IF test compared with patients with normal clinical findings (Table 2).

Four $(31 \%)$ Chlamydia-positive patients and seven $(5 \%)$ Chlamydia-negative patients complained of ocular and urethral symptoms. The sexual partners of three $(23 \%)$ Chlamydia-positive women and four $(3 \%)$ Chlamydia-negative women were known to have urethral symptoms (dysuria and urethral discharge). One of the Chlamydia-positive patients was using oral contraceptives, two had an IUD fitted, and two were pregnant, one in the first and the other in the second trimester.

Papanicolaou's cervicovaginal smears obtained from the Chlamydia-positive patients were classified as inflammatory (inflammatory cellular atypias with abundance of leucocytes) in $69 \%$ of patients compared with $42 \%$ of Chlamydia-negative patients. This difference was not however statistically significant $(P<0 \cdot 25)$.

On colposcopy, grade I-II inflammation was observed in 11 of the Chlamydia-positive patients. The histological findings were: normal cervical epithelium in four patients, ectopy area with mild, chronic infection in one, vaginitis with mild, ectocervical infection in two, and ectopy area with epidermisation in one. Colposcopic grade III inflammation was observed in two Chlamydiapositive patients. In the first instance the histological specimen showed a chronically infected ectopy area with squamous metaplasia and in the other a normal ectocervical epithelium with mild chronic and unspecific infection. Cytological and histological specimens were carefully screened for typical intracellular inclusions (Naib, 1970; Swanson et al., 1975), but none was found.

Culture for yeast infection was positive in 14 patients, and for $N$. gonorrhoeae in five patients. Genital condylomata accuminata were diagnosed in eight patients. None of these patients had concomitant Chlamydia. One of the three patients with $T$. vaginalis infection and one of the four with herpes genitalis infection also excreted Chlamydia.

\section{Discussion}

The chlamydial isolation rate of $9 \%$ in 144 women from a general gynaecological outpatient population accords with the results of Schachter et al. (1975b), who found seven $(8 \%)$ Chlamydia-positive patients out of 90 women attending a women's clinic for routine examination in San Francisco, but it is lower than the $12.7 \%$ isolation rate in women 'with symptoms' attending the same clinic (Schachter et al., 1976). A higher incidence has been found in sexually more promiscuous groups, such as patients attending venereal disease clinics and contacts of men with NGU (Hobson et al., 1974; Nayyar et al., 1976; Richmond and Sparling, 1976; Alani et al., 1977; Rees et al., 1977).

The clinical picture of overt genital chlamydial infection was frequently non-specific cervicitis and cervical erosion. Similarly, Schachter et al. (1975a, 1976) have shown genital chlamydial infection to be associated with cervicitis and cervical erosion but not with vaginitis alone. Schachter et al. (1976) found an isolation rate of $34.7 \%$ among 170 women

Table 2 Comparison of clinical cervicovaginal findings and chlamydial isolation results with seropositivity

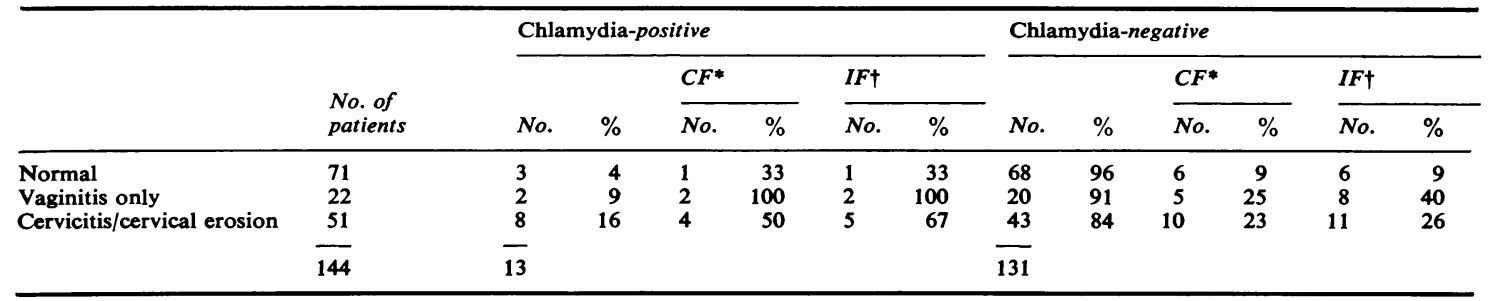

*CF test titre $\geqslant 1: 8$

†IF test titre $\geqslant 1: 64$

D 
with cervicitis. Hobson isolated Chlamydia in $63 \%$ of 35 women with hypertrophic cervical erosions (Hobson et al., 1974). We found only $16 \%$ of the patients with cervical infection harboured Chlamydia, which may be because our patients were attending a gynaecological clinic rather than a clinic for the treatment of genital infections.

Ocular and urethral symptoms were significantly more common in patients with overt chlamydial infection (excretion from the cervix) than in Chlamydia-negative patients. Other micro-organisms examined in our study could not explain these symptoms, since yeast, condyloma accuminatum, and $N$. gonorrhoeae were not detected concomitantly with Chlamydia, and herpes genitalis and $T$. vaginalis were detected in only one case together with Chlamydia.

Much attention has recently been paid to cytology as a rapid method for diagnosing viral infections. The cytological diagnosis of herpes genitalis has been established (Naib et al., 1966; Vesterinen et al., 1977). Cytomegalovirus (Vesterinen et al., 1975) and adenovirus (Vesterinen et al., 1978) can also cause specific alterations in human cervical epithelial cells in vitro. Specific cytopathic alterations induced by Chlamydia in human cervical epithelium in clinical cases have been presented (Swanson et al., 1975). In the present work special attention was paid to such alterations in cervicovaginal smear preparations and histological samples, but none was found. A non-specific inflammatory picture dominated in Chlamydia-positive cases indicating that cytomorphological methods are unrewarding in the diagnosis of genital chlamydial infections. Nonspecific inflammatory changes have been regularly found in the cervical smears of female contacts of men with NGU (Simmons and Vosmik, 1974). Naib has recognised typical clusters of intracytoplasmic inclusions in epithelial parabasal cells in addition to an abundance of leucocytes and histiocytes in cervicovaginal smears of mothers of newborn infants with suspected chlamydial infection (Naib, 1970). However, no patient in the third trimester of pregnancy was included in our study.

Determining chlamydial group-specific antibodies by the CF test only is unrewarding in genital tract infections which tend to limit themselves to the epithelium (Grayston and Wang, 1975; Richmond and Caul, 1975). We found, however, that $54 \%$ of women with proved cervical chlamydial infection had CF antibodies, compared with $16 \%$ of Chlamydia-negative women. This is in accordance with the results of Schachter et al. (1975b), who observed that $57.5 \%$ of 40 women with overt chlamydial infection had CF antibodies.
The new modification of a single-antigen IF test applied in the present study appeared to be sensitive. C. trachomatis LGV-serotype $\mathrm{L} 2$ has been shown by IF tests to give crossreaction with antibodies to most important genital chlamydial serotypes (Oriel et al., 1975). Reactive sera occurred to $85 \%$ of the Chlamydia-positive patients and in $53 \%$ of the Chlamydia-negative patients. However, only $19 \%$ of the Chlamydia-negative patients were seropositive at IF test titre $\geq 1: 64$ as compared with $62 \%$ of the Chlamydia-positive patients. Similarly, Richmond and Caul (1975, 1977), using another single-antigen IF test, noted reactive sera in $88 \%$ of culturepositive and in $49 \%$ of culture-negative women attending a venereal disease clinic.

It was noteworthy that the seropositivity rate was high among Chlamydia-negative patients with signs of cervicovaginal infection (Table 2). This may be attributed to a past chlamydial infection or to the insensitivity of current isolation methods for C. trachomatis. Perhaps the serum antibodies even at high titres are not diagnostic for an active infection, since such antibody titres are also seen in isolation-negative patients (Table 1). More knowledge about the kinetics and duration of the serological response to chlamydial infection is needed.

Non-specific genital infection in women seems to be a major epidemiological problem as a reservoir of Chlamydia, particularly because of the difficulty in identifying chronic and latent infections.

Our study gives further evidence of the pathogenicity of $C$. trachomatis in the female genital tract. The non-specific clinical and cytomorphological picture of this infection requires that reliable isolation facilities are generally available in gynaecological practice.

We wish to express sincere thanks to Mrs Hellä Sarjakivi for her technical assistance in the CF and IF antibody assays, and to Mrs Tuula Nieminen for efficiently carrying out the secretarial work. We also thank Miss Marja-Leena Kauppinen, who kindly and reliably assisted in the collection of the specimens.

This study was aided by a grant from the Paulo Foundation and Finnish Cultural Foundation.

\section{References}

Alani, M. D., Darougar, S., Burns, D. C. MacD., Thin, R. N., and Dunn, H. (1977). Isolation of Chlamydia trachomatis from the male urethra. British Journal of Venereal Diseases, 53, 88-92.

Alexander, E. R. (1973). Possible etiologies of cancer of the cervix other than herpesvirus. Cancer Research, 2, 1485-1496.

Darougar, S., Kinnison, J. R., and Jones, B. R. (1971). Simplified irradiated McCoy cell culture for isolation of Chlamydiae. In Trachoma and Related Disorders, p. 63. Edited by R. L. Nichols. Excerpta Medica: Amsterdam. 
Dunlop, E. M. C., Goldmeier, D., Darougar, S., and Jones, B. R. (1976). Chlamydia infection of the genital tract in the mothers and fathers of babies suffering from oftalmia neonatorum due to TRIC agent. In Sexually Transmitted Diseases, p. 83. Edited by R. D. Catterall and C. S. Nicol. Academic Press: London.

Dunlop, E. M. C., Vaughan-Jackson, J. D., and Darougar, S. (1972). Chlamydial infection. Improved methods of collection of material for culture from the urogenital tract and rectum. British Journal of Venereal Diseases, 48, 421-424.

Eschenbach, D. A., Buchanan, T. M., Pollock, H. M., Forsyth, P. S., Alexander, E. R., Lin, J-S., Wang, S-P., Wentworth, B. B. McCormack, W. M., and Holmes, K. K. (1975). Polymicrobial etiology of acute pelvic inflammatory disease. New England Journal of Medicine, 293, 166-171.

Grayston, J. T., and Wang, S-P. (1975). New knowledge of chlamydiae and the diseases they cause. Journal of Infectious Diseases, 132, 87-105.

Hobson, D., Johnson, F. W. A., Rees, E., and Tait, I. A. (1974). Simplified method for diagnosis of genital and ocular infections with Chlamydia. Lancet, 2, 555-556.

Leinikki, P., and Salo, O. P. (1973). Genital herpes. Virological diagnosis and antibody response. Acta dermato venereologica, 53, 65-70.

Lennette, E. H., Spaulding, E. H., and Truant, J. P. (1974). Manual of Clinical Microbiology, second edition, pp. 124-129; 491-507; 582-601. American Society for Microbiology: Washington DC

Márdh, P-A., Ripa, T., Svensson, L., and Weström, L. (1977). Role of Chlamydia trachomatis infection in acute salpingitis. New England Journal of Medicine, 296, 1377-1379.

Naib, Z. M. (1970). Cytology of TRIC agent infection of the eye of newborn infants and their mothers' genital tracts. Acta cytologica, 14, 390-395.

Naib, Z. M., Nahmias, A. J., and Josey, W. E. (1966). Cytology and histopathology of cervical herpes simplex infection. Cancer, 19, 1026-1031.

Nayyar, K. C., O'Neill, J. J., Hambling, M. H., and Waugh, M. A. (1976). Isolation of Chlamydia trachomatis from women attending a clinic for sexually transmitted diseases. British Journal of Venereal Diseases, 52, 396-398.

Oriel, J. D., Reeve, P., Thomas, B. J., and Nicol, C. S. (1975). Infection with Chlamydia group $\mathbf{A}$ in men with urethritis due to Neisseria gonorrhoeae. Journal of Infectious Diseases, 131, 376-382.

Purola, E., and Savia, E. (1977). Cytology of gynecologic condyloma acuminatum. Acta cytologica, 21, 26-31.

Rees, E., Tait, A., Hobson, D., and Johnson, F. W. A. (1977). Chlamydia in relation to cervical infection and pelvic inflammatory disease. In Non-gonococcal Urethritis and Related Infections, p. 67. Edited by D. Hobson and K. K. Holmes. American Society for Microbiology; Washington DC.
Richmond, S. J., and Caul, E. O. (1975). Fluorescent antibody studies in chlamydial infections. Journal of Clinical Microbiology, 1, 345-352.

Richmond, S. J., and Caul, E. O. (1977). Single-antigen indirect immunofluorescence test for screening venereal disease populations for chlamydial antibodies. In Non-gonococcal Urethritis and Related Infections, p. 259. Edited by D. Hobson and K. K. Holmes. American Society for Microbiology: Washington DC.

Richmond, S. J., and Sparling, P. F. (1976). Genital chlamydial infections. American Journal of Epidemiology, 103, 428-435.

Saikku, P., and Paavonen, J. (1978). Single-antigen immunofluorescent test for Chlamydial antibodies. Journal of Clinical Microbiology, in press.

Schachter, J., Causse, G., and Tarizzo, M. L. (1976). Chlamydiae as agents of sexually transmitted diseases. Bulletin of the World Health Organisation, 54, 245-254.

Schachter, J., Hanna, L., Hill, E. C., Massad, S., Sheppard, C. W. Conte, J. E., Jr, Cohen, S. N., and Meyer, K. F. (1975a). Are chlamydial infections the most prevalent venereal disease? Journal of the American Medical Association, 231, 1252-1255.

Schachter, J., Hill, E. C., King, E. B., Coleman, V. R., Jones, P., and Meyer, K. F. (1975b). Chlamydial infection in women with cervical dysplasia. American Journal of Obstetrics and Gynecology, 123, 753-757.

Schachter, J., Rose, L., and Meyer, K. F. (1967). The venereal nature of inclusion conjunctivitis. American Journal of Epidemiology, 85, 445-452.

Simmons, P. D., and Vosmik, F. (1974). Cervical cytology in nonspecific genital infection. An aid to diagnosis. British Journal of Venereal Diseases, 50, 313-314.

Swanson, J., Eschenbach, D. A., Alexander, E. R., and Holmes, K. K. (1975). Light and electron microscopic study of Chlamydia trachomatis infection of the uterine cervix. Journal of Infectious Diseases, 131, 678-687.

Timonen, S., and Meyer, B. (1967). Colposcopic and cytological diagnosis of cervical cancer and premalignant lesions. Annales chirurgiae et gynaecologiae Fenniae, 56, Supplement 158, 3-17.

Vesterinen, E., Leinikki, P., and Saksela, E. (1975). Cytopathogenicity of cytomegalovirus to human ecto- and endo-cervical epithelial cells in vitro. Acta cytologica 19, 473-481.

Vesterinen, E., Purola, E., Saksela, E., and Leinikki, P. (1977). Clinical and virological findings in patients with cytologically diagnosed gynecologic herpes simplex infections. Acta cytologica, 21, 199-205.

Vesterinen, E., Vahevi, A., Paavonen, J., and Saksela, E. (1978). Adenovirus infection and cytopathic alterations of the human cervical epithelial cells in vitro. Acta cytologica, in press. 